\title{
A high proportion of interseasonal childhood influenza cases in 2019 were travel related
}

\section{Lucy Denga, , Paula Mazzocatoc, Gemma Saravanos ${ }^{\mathrm{a}, \mathrm{b}}$, Karin Leder ${ }^{\mathrm{d}, \mathrm{e}}$ and Philip N Britton ${ }^{\mathrm{b}, \mathrm{f}, \mathrm{g}}$}

a National Centre for Immunisation Research and Surveillance, The Children's Hospital at Westmead, Sydney, NSW, Australia

b University of Sydney Children's Hospital Westmead Clinical School, NSW, Australia

c Emergency Department, The Children's Hospital at Westmead, Sydney, NSW, Australia

${ }^{a}$ Monash University, Melbourne, VIC, Australia

- Royal Melbourne Hospital, VIC, Australia

† Department of Infectious Diseases and Microbiology, The Children's Hospital at Westmead, Sydney, NSW, Australia

${ }^{g}$ Corresponding author: philip.britton@health.nsw.gov.au

\section{Article history}

Publication date: June 2020

Citation: Deng L, Mazzocato P,

Saravanos G, Leder K, Britton PN.

A high proportion of interseasonal childhood influenza cases in 2019 were travel related. Public Health Res Pract. 2020;30(2):e3022012. https://doi.org/10.17061/phrp3022012

\section{Background}

Influenza is considered a seasonal disease in temperate regions, with annual epidemics between May and October in the Southern Hemisphere and the reverse in the Northern Hemisphere. In tropical regions, influenza can circulate year round. ${ }^{1}$

In 2019, Australia experienced a higher than usual number of laboratoryconfirmed influenza cases in the months preceding the typical influenza season. ${ }^{2}$ International travellers are at risk of acquiring influenza infection when travelling to regions where the virus is circulating and importing the virus into their home country on return. These cases can function as sentinels for sustained transmission. ${ }^{3}$ Preliminary data from a case-control study found that travellers played a role in introducing influenza infection into New South Wales (NSW) in the 2018-2019 summer period. ${ }^{4}$ We aimed to describe travelrelated influenza cases presenting to a single tertiary paediatric hospital in NSW in 2019.

\section{Methods}

The Children's Hospital at Westmead in Sydney, NSW, is a GeoSentinel surveillance network associate site that systemically collects clinical information about ill returning travellers who are identified in the emergency department using a standardised case report form, as described elsewhere. ${ }^{5}$ Through this network, we identified influenza cases from returning travellers who attended the hospital between January and October 2019. An influenza case was defined as an individual with influenza infection confirmed on a respiratory sample by a polymerase chain reaction (PCR) test at the hospital. A travel-related case was defined as a case with symptom onset during international travel or within 4 days following return. Cases were excluded if testing was performed more than 48 hours following hospital admission, 
to exclude hospital acquisition, or if the patient had re-presented with a repeat positive test within 14 days of previous testing. Travel-related cases were compared with cases with no history of travel that presented to hospital over the same period. Month of travel and demographic details were compared between groups. Destination and reason for travel were described for travel-related cases.

\section{Results}

There were 879 laboratory-confirmed influenza presentations to The Children's Hospital at Westmead from January to October 2019, of which 25 (2.8\%) were travel related (see Supplementary Figure 1, available from: doi.org/10.6084/m9.figshare.12331403). One probable travel-related case, where family members were influenza A positive but the patient was not tested, was excluded.

Almost three-quarters of travel-related cases (17/25) occurred in the interseasonal period between January and April. In this period, $12.3 \%$ (17/138) of all influenza cases were travel related, compared with $1.1 \%(8 / 741)$ between May and October. This difference in proportion was statistically significant $\left(X^{2} 53.18\right.$; df 1; $N=879$; $\mathrm{p}<0.001)$. Influenza $A$ accounted for a significantly greater proportion of travel-related cases (80\%) compared with nontravel-related cases (60\%) (Table 1). The most frequent destinations for travel were India $(n=8)$, Pakistan $(n=3)$ and the Philippines $(n=3)$. The most common reason for travel was visiting friends and relatives ( $n=10)$, accounting for $67 \%(10 / 15)$ of travelrelated cases where reason for travel was known. None of the cases were known to be vaccinated for influenza before travel.

Table 1. Demographic and clinical details of influenza cases at The Children's Hospital at Westmead, JanuaryOctober 2019

\begin{tabular}{|c|c|c|c|c|}
\hline Demographic & Clinical details & All cases & Travel related & Nontravel related \\
\hline N & & 879 & 25 & 854 \\
\hline \multirow[t]{2}{*}{ Sex } & Male, $n(\%)$ & $492(56.0)$ & $15(60.0)$ & $477(55.9)$ \\
\hline & Female, $n(\%)$ & $387(44.0)$ & $10(40.0)$ & $377(44.1)$ \\
\hline Age & Median years (interquartile range) & $4.4(1.7-7.6)$ & $2.7(1.6-5.3)$ & $4.5(1.7-7.6)$ \\
\hline \multirow[t]{6}{*}{ Influenza strain } & A (total), $n(\%)$ & $531(60.4)$ & $20(80.0)$ & $511(59.8)$ \\
\hline & A subytpe $\mathrm{H} 1 \mathrm{~N} 1, n(\%)$ & $100(11.4)$ & $12(48.0)$ & $88(10.3)$ \\
\hline & A subtype H3N2, n(\%) & $112(12.7)$ & $3(12.0)$ & $109(12.8)$ \\
\hline & A not typed, $n(\%)$ & $319(36.3)$ & $5(20.0)$ & $314(36.8)$ \\
\hline & $\mathrm{B}, n(\%)$ & $346(39.4)$ & $5(20.0)$ & $341(39.9)$ \\
\hline & Both $\mathrm{A}$ and $\mathrm{B}, n(\%)$ & $2(0.2)$ & $0(0.0)$ & $2(0.2)$ \\
\hline \multirow[t]{2}{*}{ Timing of travel } & January-April, $n(\%)$ & $138(15.8)$ & $17(68.0)$ & $121(14.2)$ \\
\hline & May-October, $n(\%)$ & $741(84.3)$ & $8(32.0)$ & $733(85.8)$ \\
\hline \multirow[t]{6}{*}{ Travel destination ${ }^{a}$} & India, $n(\%)$ & & $8(32.0)$ & \\
\hline & Pakistan, $n(\%)$ & & $3(12.0)$ & \\
\hline & Philippines, $n(\%)$ & & $3(12.0)$ & \\
\hline & China, $n(\%)$ & & $2(8.0)$ & \\
\hline & Singapore, $n(\%)$ & & $2(8.0)$ & \\
\hline & Sri Lanka, $n(\%)$ & & $2(8.0)$ & \\
\hline \multirow[t]{4}{*}{ Travel reason } & Tourism, $n(\%)$ & & $3(12.0)$ & \\
\hline & Visiting friends and relatives, $n(\%)$ & & $10(40.0)$ & \\
\hline & Visiting Australiab, $n(\%)$ & & $2(8.0)$ & \\
\hline & Unknown, $n(\%)$ & & $10(40.0)$ & \\
\hline
\end{tabular}

a Destinations with single case: Fiji, Jordan, New Zealand, UK, US

${ }^{\mathrm{b}}$ From Sweden 


\section{Discussion}

Despite small numbers, our study found that travelrelated influenza in children occurred predominantly in the interseasonal period and contributed to a significantly higher proportion of cases in this period than in the usual influenza season. A large proportion of travel related to visiting friends and relatives in neighbouring Asian countries, in tropical regions where influenza can circulate year round. Because of the small number of cases and the absence of subtyping in a significant proportion of cases, we were unable to make comparisons with contemporaneously circulating subtypes worldwide. However, consistent with a larger statewide study ${ }^{4}$, our study suggests that importation of influenza by travellers may have contributed to the early spread and surge of influenza cases in NSW in 2019.

Although vaccination is the best way to protect against influenza infection, none of our travel-related cases had a documented influenza vaccination before travel. Our study suggests that influenza vaccine needs greater consideration and promotion as a travel vaccine. Travellers should receive influenza vaccine when travelling to regions where influenza is circulating or in settings with an increased risk of transmission, including large tourist groups, cruises and mass gatherings. For those who have received a current Southern Hemisphere influenza vaccine and are travelling to the Northern Hemisphere during its influenza season, a second dose of vaccine in the same year should be considered, as per updated recommendations in the Australian Immunisation Handbook. $^{6}$

\section{Conclusion}

A relatively high proportion of interseasonal influenza cases in children are travel related. Influenza vaccination for travellers should be promoted to reduce the importation and spread of influenza virus in the community.

\section{Acknowledgements}

PB received in-kind support through a National Health and Medical Research Council Early Career Fellowship (GNT1145817). KL has received payment as a member of the leadership team and Melbourne site director of GeoSentinel. GeoSentinel, the Global Surveillance Network of the International Society of Travel Medicine (ISTM), is supported by a Cooperative Agreement (U50/ CCU412347) from the Centers for Disease Control and Prevention, and funding from the ISTM and the Public Health Agency of Canada.

\section{Peer review and provenance}

Externally peer reviewed, not commissioned.

\section{Competing interests}

None declared.

\section{Author contributions}

LD performed the analysis and drafted the manuscript. PM undertook the GeoSentinel surveillance and reviewed and revised the manuscript. GS sourced data, and reviewed and revised the manuscript. $\mathrm{KL}$ reviewed and revised the manuscript. PB devised the study, designed the analysis, and reviewed and revised the manuscript.

\section{References}

1 Monto AS. Epidemiology of influenza. Vaccine. 2008;26 Suppl 4:D45-8.

2. Department of Health. Australian influenza surveillance report. No 12, 23 September to 6 October 2019.

Canberra: Australian Government Department of Health; 2019 [cited 2019 Nov 26]. Available from: www1.health. gov.au/internet/main/publishing.nsf/Content/cda-surveilozflu-flucurr.htm/\$File/flu-12-2019.pdf

3. Davis XM, Hay KA, Plier DA, Chaves SS, Lim PL, Caumes $\mathrm{E}$, et al. International travelers as sentinels for sustained influenza transmission during the 2009 influenza $A(H 1 N 1) p d m 09$ pandemic. J Travel Med. 2013;20(3):177-84.

4. Marsh C, Andrews RM, Sheppeard V, Gilmour R, Tobin S. Drivers of a summer influenza epidemic - New South Wales, Australia, 2018-2019. Canberra: Public Health Association of Australia Communicable Disease Conference; 2019 [cited 2020 Jun 8]. p. 13. Available from: 03294849-f971-41a4-9848-27a9ba197989.filesusr.com/ ugd/a52314_e5df56502c8d414eb22b 1f0ae37c4d36.pdf

5. Freedman DO, Kozarsky PE, Weld LH, Cetron MS. GeoSentinel: the global emerging infections sentinel network of the International Society of Travel Medicine. J Travel Med. 1999;6(2):94-8.

6. Australian Technical Advisory Group on Immunisation (ATAGI). People who are traveling during the influenza season are strongly recommended to receive influenza vaccine. Australian Immunisation Handbook. Canberra: Australian Government Department of Health; 2018 [cited 2019 Nov 26]. Available from: immunisationhandbook. health.gov.au/recommendations/people-who-aretravelling-during-the-influenza-season-are-stronglyrecommended-to

\section{Copyright: (C) $\underset{\mathrm{BY}}{\mathrm{BSC}} \mathbf{\mathrm { NA }}$}

(C) 2020 Deng et al. This article is licensed under the Creative Commons Attribution-NonCommercial-ShareAlike 4.0 International Licence, which allows others to redistribute, adapt and share this work non-commercially provided they attribute the work and any adapted version of it is distributed under the same Creative Commons licence terms. See: www.creativecommons.org/licenses/by-nc-sa/4.0/ 